\title{
Study on Risk Prevention Mechanism of the Quality and Safety of Agricultural Products - Based on the Perspective of Peasant Special Cooperative Organizations
}

\author{
Yanfen Dou \\ Department of Economics and Management, Tianjin \\ Agricultural University \\ Tianjin, China \\ bbdd_2006@126.com
}

\begin{abstract}
The paper analyzes the cooperatives' effectiveness in ensuring the quality and safety of agricultural products, discusses specific mechanism design problems of peasant special cooperative organizations' preventing the risk of the quality and safety of agricultural products and puts forward to the main countermeasures to promote the organizations to play their role in safeguarding the quality and safety of agricultural products, which can be used as decision-making reference for the relevant sectors.
\end{abstract}

Keywords-peasant special cooperative organizations, quality and safety of agricultural products, risk prevention

\section{INTRODUCTION}

As the source of food, the quality and safety of agricultural products is directly related to people's physical health and life safety, and has become the most important livelihood issue and a focus that draws the most attention. In recent years, from the results of the quality inspection of agricultural products, the level of the quality and safety of agricultural products rise steadily in China, but the frequency of food safety events proves that there are still serious risks with the quality and safety of our agricultural products. It is still a major issue to guarantee the quality and safety of agricultural products from the source.

In recent years, peasant special cooperative organizations have taken on a trend of rapid development. From 2008, the number of peasant special cooperative organizations grows rapidly at the speed of 10,000 per month, and by the end of 2012 , it reaches 689,000 . The organizations solve key issues faced by farmers such as technology, information, market, improve their ability to resist risks, and allow them to move successfully from the "little production" to the "big market", and have become an important force to develop modern agriculture, promote farmers' income, and prosper the rural economy. The cooperatives' organizational characteristics, collective behaviors and standardized and specialized largescale production mode are conducive to avoid the risk of the quality and safety of agricultural products on whole industry chain and play an increasingly important role in safeguarding the quality and safety of agricultural products.

\author{
Yan Jiang, Qiang Miao \\ Department of Economics and Management, Tianjin \\ Agricultural University \\ Tianjin, China \\ Jiangy66@163.com
}

II. THE QUALITY AND SAFETY OF AGRICULTURAL PRODUCTS IS A STRATEGIC ISSUE CONCERNING CHINA'S FUTURE DEVELOPMENT

With the acceleration of china's urbanization, industrialization and agricultural modernization processes, the economic and social development achievements in the urban and rural areas win the world attention. As the urban and rural residents raise their income level and pay constant attention to their life quality, they have put forward higher requirements for the quality and safety of agricultural products and their pursuit for healthy safe agricultural products has become more desirous. However, the events of "the tainted milk", "clenbnterol hydrochloride", "the fermentation liquor plasticizing agent", and "fast-growing chicken", have bring continued panic and sense of crisis to the public. According to the findings of China's Overall Well-off Research Center of the "Well-off" Magazine, in the construction process of comprehensive well-off society, "food security" ranked in the first place in the ten focuses that drew most public attention in 2012, and food quality and safety is a major current concern of the public. Public evaluation of the food security situation is shown in Figure 1: $33.9 \%$ of respondents perceived "not very satisfied"; $24.8 \%$ of them perceived "very dissatisfied"; $26.0 \%$ of them felt "ordinary"; only $15.3 \%$ of the them felt "satisfied" and "very satisfied". As can be seen, public satisfaction on the food quality and safety is not high, and people are looking forward to safe food. Since agricultural products are the source of food, their quality and safety is directly related to people's health and life safety, and undoubtedly become the most important livelihood issue that relates to 1.3 billion people.

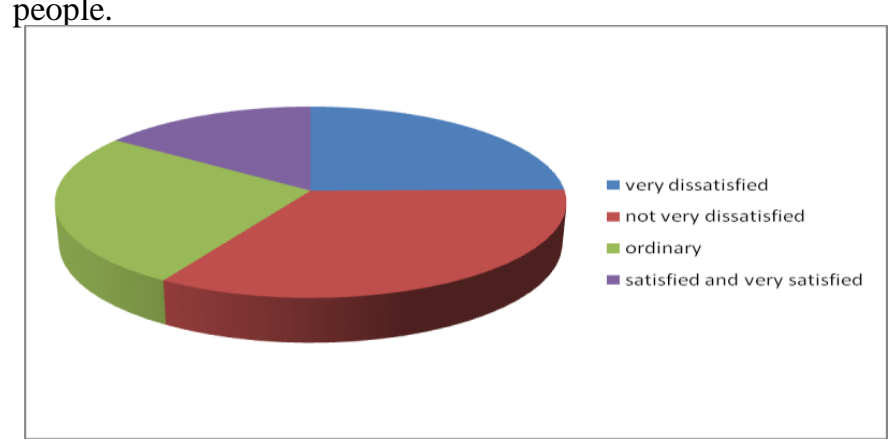

Figure 1. The chinese public evaluation of food security situation in 2012(\%) 
Agriculture is a country's basic industry, and due to the presence of multiple risks, it is also a vulnerable industry. The issue of the quality and safety of agricultural products, affects the development of agriculture and farmers' income, and sometimes even destroys the whole industry. From historical experience, events of agricultural product quality and safety will also directly affect the public's trust in the government, and a major security incident even undermines social stability and endangers national security. The BSE case in Germany and the dioxin incident in Belgium are two good cases, which not only affect social harmony, but also challenge the governments' credibility. In China with the population of 1.3 billion, it is directly related to the construction of the comprehensive well-off society and is an important ruler to measure the transformation of government functions at all levels. In recent years, with the continuous efforts and concerns of all sectors of society, the overall development of agricultural product quality and safety is in good shape. Figure 2 shows the monitoring situation of the quality of vegetables, livestock products and aquatic products from 2009 to 2011, and we can draw conclusion that the level of quality and safety is raised steadily in general. However, the problem has not been completely resolved, its potential risks are not completely eliminated, and its situation is still not optimistic. Central Economic Work Conference, which was recently concluded, especially proposed that the quality and safety of agricultural products should be ensured from the source. It is a major strategic issue for China's future development to ensure the safety of the agriculture industry and agricultural products' consumption, minimize the risk of agricultural product quality and safety and take preventive rather than remedial measures.

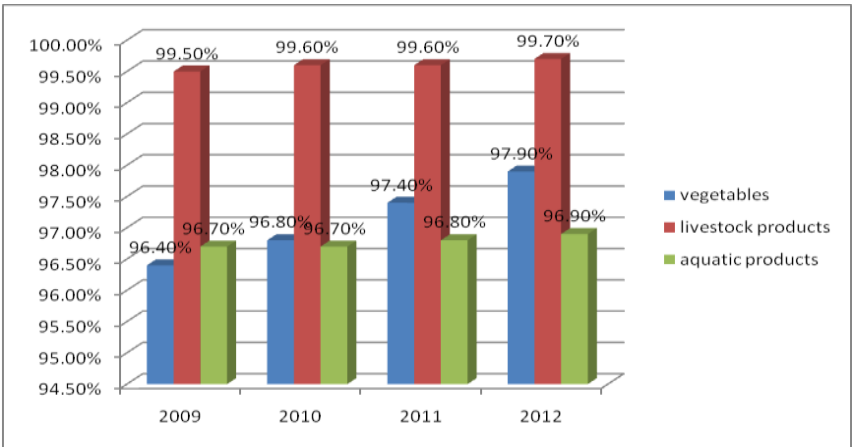

Figure 2. The qualification rate of agriculture products from 2009 to 2011 in China(\%)

\section{ANALYSIS OF THE EFFECTIVENESS OF PEASANT SPECIAL COOPERATIVE ORGANIZATIONS' PROTECTING THE QUALITY AND SAFETY OF AGRICULTURAL PRODUCTS}

Farmers' specialty cooperatives, one kind of China's rural cooperative organizations, take on rapid growth momentum. 521,700 cooperatives including 41 million families are registered in the national industrial and commercial sectors by the end of the year of 2011 , which accounts for $16.4 \%$ of the total number of households.
The cooperatives organize millions of scattered peasant households, resolve the technology, information, market and other key issues faced by farmers, increase their ability to resist risks and take part in market games, and effectively ensure the quality and safety of agricultural products and promote farmers' income and sustainable development of agriculture by full-services of the supply of the means of production, the promotion of agricultural technology, standardized production and marketing of agricultural products [1].

Guo-yuan Ren et al (2008) conducted a survey of the performance of rural cooperative economic organizations in the quality control of agricultural products in Jiaxing City of Zhejiang Province. The survey shows that the sampling pass rates of livestock and poultry, aquatic products, vegetables, and pigs were $91 \%, 100 \%, 97.5 \%$, and $99.2 \%$ in 2005 , and the pass rates of those supplied by the agricultural cooperatives are $100 \%$. The survey also shows that the pass rates of the four products are $99.2 \%, 92.2 \%, 99 \%$ and $99.5 \%$ and the pass rates of those supplied by the agricultural cooperatives are still $100 \%$ in 2006 [2]. The survey results show that cooperative organizations' control of the quality and safety of agricultural products is fruitful. Specifically, the role of farmer specialized cooperative organizations in the protection of the quality and safety of agricultural products is showed in the following.

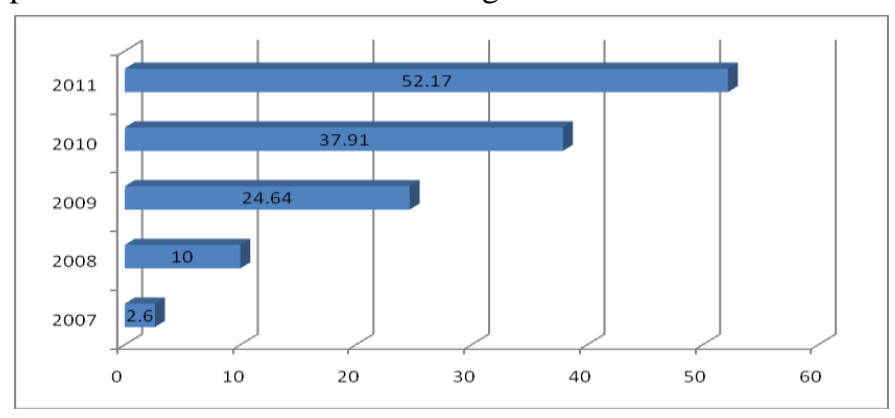

Figure 3. The growth of farmers' specialty cooperatives from 2007 to 2011 in China (ten thousant)

\section{A. Peasant Special Cooperative Organizations Whose Organizing Features Make Their Behaviors Have A Dual Nature, Can Take the Social Benefits Into Account}

Farmers' specialized cooperatives in China, as well as widespread international cooperative enterprises, adhere to the basic philosophy of cooperation, core values, and integratedly display characteristics different from general corporate organizations, namely: identity characteristics, mutual aid characteristics, service characteristics democratic characteristics. Their core is to seek common economic and social interests of the members on a fair and democratic method and their organizing features also prove that their acts also have economic and social duality. It is on the sense of social benefits that we believe that enterprises engaging in the production of agricultural products and food also manage their moral conscience, and the cooperative enterprises with dual attributes whose opportunistic tendencies are much weaker than that of general corporations, will pay more 
attention to the quality and safety of agricultural products in social benefit sector in order to get more social identity [3].

B. The Collective Behaviors of the Cooperative Organizations Can Effectively Circumvent the Agricultural Product Quality And Safety Problems That Decentralized Management of Small Farmer Households Bring

Decentralized management of small farmer households is the basic characteristics of China's agricultural production. According to the survey of Agricultural Economics, China currently has 250 million peasant households who operate an average of 0.55 hectares of land much lower than Canada and Australia's farmers whose family farm scale is on an average of more than 2000 hectares, and also lower than 169 hectares in the United States, 30 to 40 hectares in the European Union, 1.84 hectares in Japan and about 1.0hectare in Korea and Taiwan. Farmers with less than 10 acres of arable land account for $74.2 \%$. Decentralized management of small farmers has many difficulties in ensuring the quality and safety of agricultural products, whose lack of economic strength may bring improper or inadequate technology applications. It is difficult for many scattered small-scale farmers to form a specialized, standardized, large-scale production, which results in increase of the quality and safety risk of agricultural products. At the same time, the government regulatory capacities become insufficient and the quality is not easy to control because of so many dispersed farmers, which also requires the government to strengthen social collaboration and governance.

Farmers' cooperative organizations on the basis of household contract management are mutual aid economic organizations where farmers achieve "self-management, selfservice, self-benefit". The organizations not only have a common philosophy and core values. Furthermore, the organizations in China also include the human-oriented factors of "blood", "geo" and "relatives". So compared with foreign cooperation organizations, farmers of China's cooperative organizations are not only easier to have common goals and philosophy but also easier to form team spirit and launch collective action and to strive to set a positive image in the market for long-term survival and development in order to win good reputation and sustainable benefits. The value orientation of farmers is conducive to evade quality risks on the whole industry chain of the agricultural products and protects the quality and safety of agricultural products. Farmers' cooperative organizations effectively systemize atomized farmers, which can effectively avoid the quality and safety risk of agricultural products brought by the decentralized management of farmers, achieve scale economy, standardization, specialization of production, and facilitate the docking with government regulations. At the same time, farmers' cooperatives do not need capital verification, and are easier to achieve many forms such as farmer-supermarket docking, farmer-enterprise docking and farmer-school docking to establish a stable market supply and demand. Direct dockings of farmers and marketing, force the farmers to supervise each other so that the source control and monitoring of the quality and safety of agricultural products in advance can be achieved.

\section{Farmer Cooperative Organizations Become Supplement of Quality and Safety Supervision System of Governments}

The quality and safety of agricultural products has the basic properties of public goods, so the government should bear the primary responsibility for the supervision. There are still many deficiencies with our current system, the performances of which are the imperfect system, imperfect law, disintegration of testing standards, effortlessness of law enforcement, backward means of detection, function duplication of inspection departments and lack of their cooperation and communication. From the current situation, the national sector alone is not enough to maintain the quality and safety of agricultural products, and the thirdparty organizations such as guilds, associations, cooperative organizations, should play their role in testing, development of standards, regulation, certification. In other countries, most quality standards of agricultural products, in addition to a small number of mandatory standards related to personal safety, have been developed by industry associations. In the United States more than 400 trade associations have been involved in the development of quality standards of agricultural products. The peasant special cooperative organizations of China also actively take part in the development of quality standards of agricultural products, play an increasingly prominent role in terms of quality and safety supervision, and will be an important complement to government regulatory regime.

\section{MECHANISM DESIGN OF IMPROVING FARMERS' COOPERATIVE ORGANIZATIONS IN TERMS OF THE QUALITY AND SAFETY RISK PREVENTION OF AGRICULTURAL PRODUCTS}

\section{A. Establishing the Quality and Safety Traceability Mechanism of Farmers' Cooperative Organizations}

Traceability mechanism is an important foundation for effective supervision of the quality and safety of agricultural products. Through the establishment of a complete agricultural production files, specialized cooperative organizations of farmers record all kinds of information of the production process such as the production environment, sources of varieties, pesticides and chemical fertilizer harvesting and storage, and save the information, so that when quality and safety problems occur,the specific production farmers can be dated back to based on the information records [4]. The quality and safety of agricultural products can be effectively ensured from the source and the moral hazard of farmers can be avoided. Yufahuinong agricultural production-marketing professional cooperative in Beijing, founded in August 2007, have established long-term relationship with Wal-Mart and conducted quality control by the establishment of memberagricultural product quality files. When members hand in fruits, the cooperative labels the basic information of the members at uniform packaging. In the event of quality 
problems, the individual can be traced directly to. Due to the traceability mechanism, quality problems never happened in the process of its cooperation with Wal-Mart. Only 26,000 professional cooperatives achieve quality traceability of agricultural products in China. More cooperative organizations' establishing quality traceability systems is looked forward to in the future, to prevent the risk of the quality and safety of agricultural products to the maximum limit.

\section{B. Improving the Quality Regulation Mechanism of Rural Cooperative Organizations}

In essence, the cooperatives' interests and that of farmers are closely related, so farmers have a source of power to maintain and control the quality of agricultural products of the cooperatives, but it does not completely avoid speculation of farmers' non-secure production. The organization must establish and improve the quality regulation mechanisms to ensure the quality and safety. The regulatory mechanism should mainly include two aspects: First, the cooperatives' supervision against farmers should be strengthened, which involves strict management of production behaviors and processes concerning the quality and safety of agricultural products including detection and monitoring of producing environmental before production, the supervision of the pesticides and chemical fertilizer's application during the production process, and standardized management of picked products after production, to avoid the quality and safety problems. Second, cooperative organizations should reduce management costs and enhance management efficiency through improving the oversight mechanisms among the members. Bundled management should be conducted among the members and associated accountability should be investigated once there is a quality problem, which will carry out mutual supervision to protect their own interests.

\section{Perfecting the Inspection Mechanism of Rural Cooperative Organizations}

The primary task of the organizations is to ensure that farmers' products are smoothly sold, so the quality inspection and testing is one of their main tasks. "Agricultural Product Quality Safety Act" also requires farmers' specialized cooperative organizations to perform a self-test on the quality and safety of agricultural products before sale. Therefore, the organizations with relevant condition should set up their own inspection and testing institutions to detect their own products, so that on the one hand the quality security of the sold products can be ensured, which lay the foundation for maintaining credibility and building brand, and on the other hand the members can be also urged to produce safe agricultural products. For the sake of their long-term development, the organizations can also send their products to Agricultural Products Quality Inspection and Testing Centers of the agricultural sectors to test and the inspection reports issued by the centers can be used as a means to improve product quality reputation, to increase market competitiveness. Through the perfect inspection mechanism, the organizations can find product quality issues and correct them in time.

\section{Smoothing the Information Transmission Mechanism of Farmers' Cooperative Organizations}

Smooth information transfer mechanism can change the post-processing into prior management, which can effectively eliminate the unsafe quality events. Reaction of the terminal consumers to the quality of agricultural products can be passed quickly by dealers to the cooperatives, and the cooperatives uniformly adjust production according to the quality requirements of consumers, such as improvement of production environment, the introduction of high yield, good appearance and strong resistance safe varieties, the election and bought of pesticides and fertilizers and scientific usage of them with direction to farmers. Thus, farmers' agricultural production accords to the requirement of consumers from the beginning, rather than adjusts the production after unsafe incidents. The smooth information transmission mechanism makes the organizations manage the quality and safety of agricultural products from after the events to before the ones and from passive management to active management.

\section{Countermeasures to Promote Peasant SPecial COOPERATIVE ORGANIZATIONS TO PLAY A MAJOR ROLE IN SAFEGUARDING THE SAFETY OF AGRICULTURAL PRODUCTS}

\section{A. Developing and Growing Peasant Special Cooperative Organizations}

Domestic and international development practice has proved that peasant special cooperative organizations are the most direct and effective economic organizations which guide, organize and help farmers to enter the big market as well as to protect security of agricultural products from the source. The first document of the CPC Central Committee in 2013 has proposed that special cooperative organizations should be developed with greater efforts and faster paces and leading and driving capacity and market competitiveness of the organizations should be enhanced practically in accordance with the requirements of positive development, gradual standardization, consolidation of support, and promotion of quality. So, the government should take new breakthroughs in terms of finance, taxation, banking, land, develop various types of support policies urgently and increase support with more efforts to ensure peasant special cooperative organizations with a good environment for development. The development of cooperatives should conscientiously implement "Agricultural Product Quality Safety Act", give full play to their organizational and institutional advantage in the quality and safety control, organize cooperatives to promote the implementation of agricultural standardization, and uniformly develop and implement the safety standards of quality and production in accordance with the requirements that standards are adopted if there are standards and standards are set, if there are no standards, so that standardized production, safe products and branding marketing, can be achieved and cooperatives become the main part and fresh troops in agricultural production safety control [5]. 


\section{B. Enhancing Peasant Special Cooperative Organizations, Capacities of Safety Production}

The management level of cooperatives should be enhanced, and the management system of the quality of agricultural products should be established and perfected from top to bottom within the cooperatives. The management system of agricultural product quality and safety, technical operation of agricultural production and agricultural product quality monitoring system should be established and improved, which makes every cooperative to establish agricultural product traceability system. The training intensity of farmers' safe production should be increased, and agricultural product quality and safety training of cooperatives should be took into the training of farmers. Training of the knowledge of the quality and safety to cooperatives and members should be strengthened, to advance their sense of the quality and safety and to enhance agricultural production safety control.

C. Guiding and Encouraging of Farmers' Cooperative Organizations to Develop Pollution-Free Agricultural Products, Green Food, Organic Agricultural Products, and Agricultural Products with Geographical Indications.

To step on a new stage, cooperatives must have their own brand advantages. The modern market competition has entered a new era of brand competition, and without a brand that enjoys the popular, it is difficult to get recognized by the market and consumers and the market share will not be increased. Pollution-free agricultural products, green food, organic agricultural products, and agricultural products with geographical indications, are important symbols of agricultural standardization and industrialization, and have explored a set of effective methods in aspects of promoting the purification of agricultural production environment, regulation of the use of agricultural inputs, the implementation of the production process records, strict quasi-origin and build-up of market access and become a powerful means of preventing the events of the quality and safety of agricultural products. Relevant data show that Only 46,000 cooperatives get their trademarks registered, 31,000 cooperatives pass product quality certification such as pollution-free agricultural products, green agricultural products, organic agricultural products, and 1523 cooperatives pass the certification of agricultural products with geographical indications. Governments at all levels should strive to guide and encourage cooperatives to declare certifications of pollution-free agricultural products, green food, organic agricultural products, and agricultural products with geographical indications, appropriately reduce certification costs, and give a certain percentage of subsidies. Various types of rural cooperative organizations, should draw the support from governments to continually excavate the advantages of local resources, construct large-scale production bases, implement standardized production, carry out the quality and safety certification, develop more pollution-free agricultural products, green food, organic agricultural products, and agricultural products with geographical indications, constantly improve the added value of agricultural products, and fully enhanced safety and market competitiveness of agricultural products, in accordance with requirements of high quality, safety, ecology and high efficiency.

\section{ACKNOWLEDGMENT}

Supported by the major program of social science of Tianjin Education Commision: Study on countermeasures for the construction of socialization service system of Tianjin urban modern agriculture.

\section{REFERENCES}

[1] Qi Ouyang, Guiran Shi, Game Analysis of Rural Cooperative Organizations' Role to the Quality and Safety of Agricultural Products, Rural Economy, 2012(11)

[2] Guoyuan Ren, Yongyuan Ge, Analysis of Rural Cooperative Economic Organizations' Mechanism in the Quality and Safety of Agricultural Products- Jiaxing of Zhejiang Province as an Example, Issues in Agricultural Economy, 2008 (9)

[3] Longbao Wei, Xianming Lu, Analysis of Rural Cooperative Organizations' Role to the Control of the Quality and Safety of Agricultural Products-some of Cooperatives of Zhejiang as Examples, Proceeding for the International Symposium "Food Safety: Consumer, Trade, and Regulation Issues"

[4] Jianxin Zhao, Junge Wang, Analysis of Agricultural Products Quality Control Mechanisms of Farmer' Special Cooperative Organizations, Rural Economy, 2010(3)

[5] Elinor Ostrom, Institutional Incentives and Sustainable Development, 2000, Shanghai: Shanghai Joint Publishing 